\title{
Decision support systems for the management of hazardous materials in aquatic ecosystems
}

\author{
Hee-Sun $\mathrm{Cho}^{1}$ and Young-Seuk Park ${ }^{2, *}$ \\ ${ }^{1}$ Graduate School of Environmental Studies, Seoul National University, Seoul 151-742, Korea \\ ${ }^{2}$ Department of Biology, Kyung Hee University, Seoul 130-701, Korea
}

\begin{abstract}
Many aquatic ecosystems suffer from anthropogenic disturbances, including the introduction of damaging levels of toxic substances. The effects of disturbances include complex relations with various components involved in the systems, and can include physical, chemical, and hydrological disruption depending of the contaminant. Decision Support Systems (DSSs) are developed to help decision makers to deal with complex management crises, through the systematic structuring and evaluation of decisions, and through providing easy-to-use and integrated tools for information elaboration and display. We reviewed various DSSs developed for toxic substances in aquatic ecosystems, and suggested a conceptual framework which is best suited to the management of such issues within Korea. It may assist stakeholders with their decision making process, and in the achievement of a consensus on water management solutions.
\end{abstract}

Key words: aquatic ecosystem, conceptual framework, decision support systems (DSSs), hazardous materials, water management

\section{INTRODUCTION}

Historical water management often focused on watershed development and economic activities at the expense of water quality (Heathcote 1998). However, continuous urban development and increased human disturbance affect water quality and quantity, as well as threaten human health and ecological status of our freshwater systems. Protection of aquatic ecosystems from the introduction of hazardous materials is a major issue in natural water resource management, and is essential to sustain both human and ecological communities. Increasing interests with regard to water quantity and quality has led to the popularization of integrated approaches to water management, which include all water-related impacts (Achleitner et al. 2005).

One approach to water management is to aggregate several models into an integrated computer program-a
Decision Support System (DSS) - that focuses on the interaction between the users and the data, models, and the facilities which are available (Davis et al. 1991, Andreu et al. 1996, Fredericks et al. 1998). The general objective of a DSS, regardless of frameworks, methodologies, or the techniques which are used, is to provide timely information which supports human decision makers - at all levels of decision making (Loucks 1995), and such systems necessarily require all relevant information for their successful development (e.g., Eom and Lee 1990, Hodges 1991, Loucks 1992, Walker 1993). The development of a DSS can be of great benefit to the protection of environment and water resources (Labadie et al. 1989, Loucks and da Costa 1991, Santos 1991, Allen et al. 1992).

It has been reported that water resource models and DSSs do not provide satisfactory solutions in practice

\section{Open Access http://dx.doi.org/10.5141/JEFB.2012.041}

This is an Open Access article distributed under the terms of the Creative Commons Attribution Non-Commercial License (http://creativecommons org/licenses/by-nc/3.0/) which permits unrestricted non-commercial use distribution, and reproduction in any medium, provided the original work is properly cited. pISSN: 1975-020X eISSN: 2093-4521
Received 25 September 2012, Accepted 20 October 2012

*Corresponding Author

E-mail: parkys@khu.ac.kr

Tel: +82-2-961-0946 


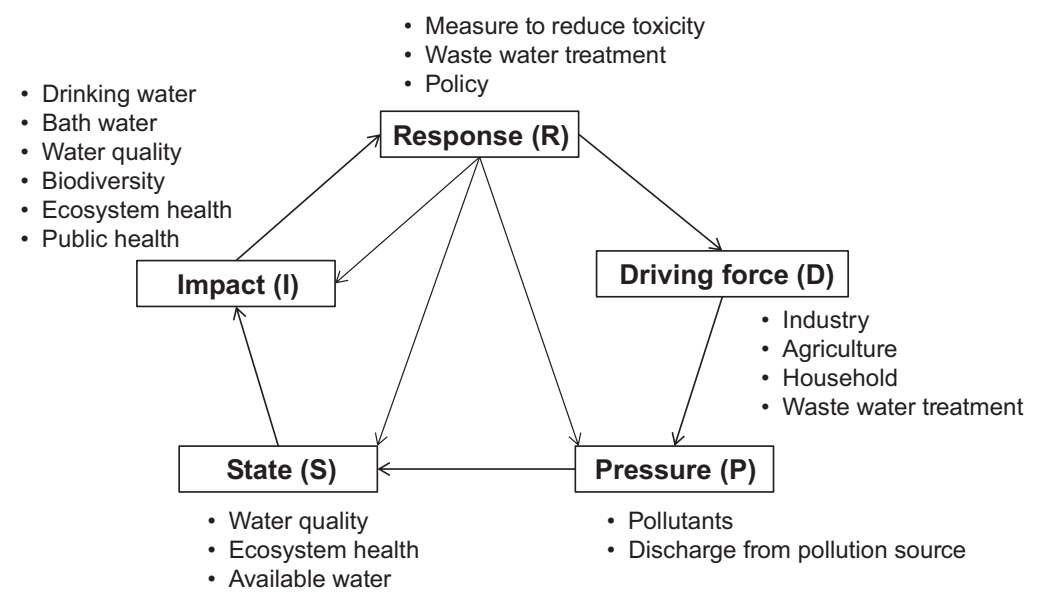

Fig. 1. Schematic diagrams of DPSIR framework for assessing toxic substances in aquatic ecosystems.

(Kim et al. 2007), although there are many contrasting studies in this field. Only 10 to $20 \%$ of developed DSSs are judged perform successfully (Organizational Aspects of Information Technology Special Interest Group 1996), indicating that the majority of DSSs have been developed under academic environments and are limited in their flexibility, or in their appreciation of a user's experience or situation (Mysiak 2005). In this study, we aimed to review the development of DSSs for toxic substances in aquatic ecosystems, and their characteristics, in order to provide a conceptual framework suitable for application to Korea.

\section{DEVELOPMENT OF DECISION SUPPORT SYSTEMS}

The use of computerized quantitative models to assist in decision making and planning began in the 1960s (Raymond 1966, Turban 1967), and a major historical turning point was the study of Scott Morton's (1967), which involved building, implementing and testing an interactive model-driven management decision system (Power 2007). DSSs were originally developed for the business and management fields, and were then expanded to various other fields which required strategic decision making and management of complex situations (Power 2009).

DSSs for the study of water resource problems began to appear in the mid-1970s, and have been widely discussed throughout literature since the mid-1980s (e.g., Stansbury et al. 1991, Ford and Killen 1995, Dunn et al. 1996, Jamieson and Fedra 1996a, 1996b, Reitsma 1996, Arumugam and Mohan 1997, Ito et al. 2001, Westphal et al. 2003).

DSSs help decision makers in structuring and evalu- ating decisions, by providing easy-to-use and integrated tools for information elaboration and display (Loucks 1995, Watkins and McKinney 1995, Jansen et al. 2002, Shim et al. 2002, Lahmer 2004). The concept of DSS has since been applied to various environmental fields in order to help decision-makers to answer specific questions by facilitating the use of various models and databases in an interactive manner (Andreu et al. 1996). The main functions of DSS are usually to provide appraisal of planning variants, to simulate scenarios with numerical modeling, and then to aid the stakeholders' judgment and the achievement of a consensus on a management solution. The DSS performs these functionalities (i.e., creation and comparison of scenarios) by combining different modeling tools and participatory processes (Jansen et al. 2002). A common functionality of DSS is also to interoperate different temporal and spatial scales (Dietrich et al. 2004).

The European Environment Agency (EAA) has developed a conceptual framework for water and river basin management, named Driving forces, Pressure, State, Impact, Response (DPSIR) (European Environmental Agency 1999). The DPSIR framework is useful for describing the relationships between the origins and consequences of environmental problems, and is also beneficial in the investigation of the links between DPSIR elements (Fig. 1). The DPSIR framework has been instrumental in the implementation of the European Water Framework Directive (WFD) (European Union 2000), due to its ability of identify and study the interactions between the environment (states and impacts) and human activities (driving forces, pressures and responses) (Dietrich et al. 2004). An example of the DPSIR framework for assessing toxic substances is shown in Fig. 1. 
Power (2007) categorized DSSs into six types following a broad historical progress of DSS research: 1) Modeldriven DSSs emphasize access to, and manipulation of optimization and/or simulation models. Simple quantitative models provide the most elementary level of functionality. Model-driven DSSs use limited data and parameters provided by decision makers to aid decision makers in analyzing a situation, but in general, large databases are not needed for model-driven DSSs. 2) Datadriven DSSs emphasize access to, and manipulation of a time-series of internal data, and sometimes external and real-time data. Simple file systems are accessed by query and retrieval tools, providing the most elementary level of functionality. 3) Communications-driven DSSs use network and communications technologies to facilitate decision-relevant collaboration and communication. 4) Document-driven DSSs use computer storage and processing technologies to provide document retrieval and analysis. 5) Knowledge-driven DSSs can suggest or recommend actions to managers. These DSSs are personcomputer systems with specialized problem-solving expertise, consisting of both knowledge about a particular domain and skills at solving some of these problems. 6) Web-based DSSs were developed with the emergence of the world-wide web and global internet, providing a technology platform for further extending the capabilities of such systems, and the deployment of computerized decision support.

\section{REVIEW ON EXISTING DECISION SUPPORT SYSTEMS}

The development of information and communication sciences has led to the development of various DSSs for aquatic ecosystem management, implementing assessment and management concepts in Europe, USA, and so on. They have adopted the legal requirements of the relevant countries: for example, all the proposed themes and functionalities of the European Union (EU) are usually related to the implementation of European legislation requirements, and particularly the EU WFD. Such functionality provides for special attention to be paid to regional water quality issues, and links between ecological and socio-economic aspects (Agostini et al. 2006), and as such, the majority of European systems have adopted the DPSIR framework (European Environmental Agency 1999). Agostini et al. (2006) proposed a management planning cycle in three stages: assessment, management, and monitoring. The assessment stage has four phases: characterization, classification, ecological state definition and quality objectives definition. The monitoring stage includes a surveillance monitoring, an investigative monitoring and an operational monitoring.

Here we reviewed selected DSSs developed for the management of river basin pollution incidents. The AQUATOOL developed in Spain is a generalized DSS (http://upv.es/aquatool), and its main functionality is the simulation of operational management. Initially, it was designed for the planning stage of decision-making in complex basins comprising multiple reservoirs, aquifers and demand centers. Later, the system was expanded to incorporate modules for the operational management stage of decision-making. AQUATOOL is currently being used by several river basin agencies in Spain as a standard tool, not only to develop their Basin Hydrological Plans, but also to manage to their water resources in an effective way. The structure of AQUATOOL is based on the separation of components and functions of a water body, leading to a highly flexible design, implementation, and operation of the system. The Windows-based DSS consists of modules for basin management simulation and optimization, modeling of water flows in aquifers, risk assessments, and analysis and reporting.

Generally, DSSs have two main functionalities: integration capabilities and evaluation of management scenarios. The main objective of systems is the management of the river of interest, and thus, many systems integrate models for ecological assessment with socio-economic evaluation, by producing possible management scenarios (Agostini et al. 2006). For example, Havel River DSS (http://www.havelmanagement.net/Havel-eng), which was developed in Germany, provides a representation of the actual state of the river by using eco-hydrological models, and a cost-benefit analysis for socio-economic evaluation. A multi-criteria analysis (MCA) is also used to evaluate future water resource management policies at the regional level (Lahmer 2004).

The management and rehabilitation of contaminated sites are complex processes, encompassing environmental, technological, and socioeconomic aspects. In order to facilitate this complex decision process, MCA plays a key-role in helping both experts and decision maker, and its importance in the overall decision making process is universally accepted, especially in the consideration of environmental pollution incidents (Giove et al. 2007). Havel River DSS enables stakeholders, decision makers, and the relevant authorities to evaluate management options and to assess the effects of man-made changes on water quantity and quality (Lahmer 2004). 


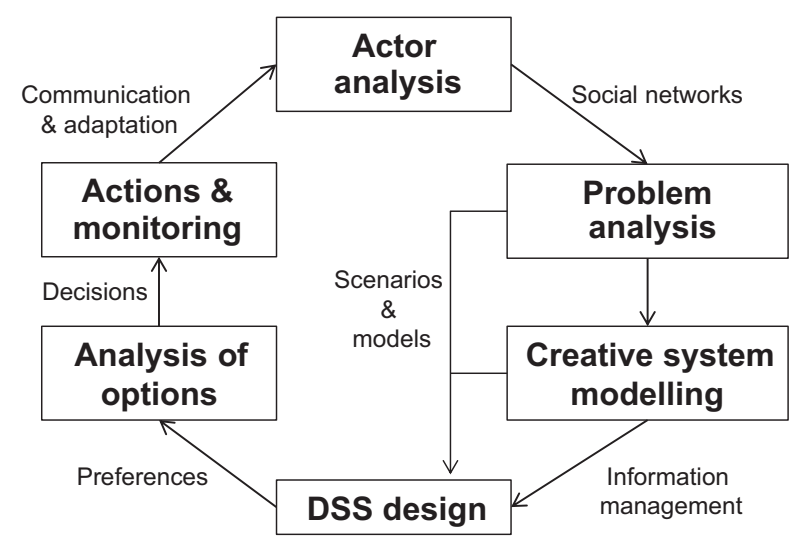

Fig. 2. Schematic diagram of NetSyMoD methodological framework. DSS, Decision Support Systems.

MCA is also used in the Multi-sectoral, Integrated and Operational Decision Support System (MULINO DSS) for Sustainable Use of Water Resources at the Catchment Scale) (http://siti.feem.it/mulino). Based on MULINO (Giupponi 2007), mDSS (http://www.netsymod. eu/mdss) was developed to assist decision makers in the management of environmental problems. It can help users, such as disciplinary experts, policy/decision makers, other stakeholders, 1) to better understand the problem at hand, 2) to explore possible decision options, also within the contexts of alternative scenarios, 3) to facilitate public participation, 4) to resolve conflicts related to alternative opinions of the correct course of action to be taken, and 5) to extend collaboration with and within different stakeholder groups. The mDSS is one of the tools for the implementation of the methodological framework NetSyMoD (http://www.netsymod.eu), standing for "Network analysis-Creative system modelling-Decision support." The processes have been formalized and described in many different ways, with probably only one main common feature, consisting of their cyclic form. Target users of NetSyMoD are researchers and policy/decision makers who aim to find particular information about research projects. Fig. 2 shows how such NetSyMoD processes can be formalized as an interactive process with the focus, as the sequence of 6 main phases: Actors analysis-Problem analysis-Creative system modelling-DSS designAnalysis of options-Action and monitoring.

The integration of different information is important in DSSs such as Better Assessment Science Integrating point and Non point Sources (BASINS) developed in USA (http://www.epa.gov/OST/BASINS) and DEcision Support sYstem REhabilitation (DESYRE) developed in Italy (http://www.veneziaricerche.it/en/progetti/progetto/
items/DESYRE.html). BASINS includes a database of cartographic data (e.g., hydrographic boundaries, network of major highways, administrative boundaries) and environmental data (e.g., soil information, drainage networks, land use, etc), and other data (Agostini et al. 2006). It assesses large amounts of point source and non-point source data, and allows the user to assess water quality at selected stream sites or throughout the entire watershed (U.S. Environmental Protection Agency 2004). The GIS-based software DESYRE integrates environmental and technological databases, risk assessment models, and multi criteria procedures (Critto et al. 2006). It allows active participation of both experts and stakeholders (Giove et al. 2007). DESYRE initially provides assessment modules for experts composed of risk assessors, socioeconomists, and technology engineers. The experts are supported from site characterization to socio-economic valuation and technology evaluation. DESYRE was also designed to provide tools for comparing alternative remediation scenarios (Carlon et al. 2007).

FLUMAGIS (http://www.flumagis.de), developed in Germany, has a powerful visualization functionality, through using 2D and 3D-geodata from a GIS environment (Moltgen and Rinke 2004). FLUMAGIS is intended for the interdisciplinary development of methods and DVtools in support of the planning and management of river basins. Editing virtual environments makes it possible to elaborate future planning and management scenarios on the basis of an interdisciplinary data and knowledge platform, in accordance with the EG-WRRL. Furthermore the integration of GIS services, micro- and meso-scale simulation models, and the derivation of ontology based measures are incorporated into the software.

DSS-ERAMANIA was developed in Italy for integrated ecological risk assessment of contaminated sites according to the Weight of Evidence and the Triad approaches, and consisted of two modules: Comparative Test Tables and Integrated Ecological Risk Indexes (Giove et al. 2007). The former aims to compare the different tests or Triad LoEs (Lines of Evidence) belonging to three investigated experimental areas (chemistry/bioavailability, ecology and ecotoxicology), and to guide the expert/decision maker in the choice of the most suitable set of tests to be applied to the case study (Semenzin et al. 2007). The latter module provides qualitative and quantitative tools which allow for assessment of terrestrial ecosystem impairment by integrating the heterogeneous information obtained by the LoEs application (Giove et al. 2007). It includes the integrated effect index, the ecosystem impairment matrix, and the global ecosystem impairment evaluation 
matrix (Semenzin et al. 2007).

Modelkey DSS (http://www.modelkey.org) describes general phases and objectives of the assessment and management of river basins. The system ranks toxicants in the river basins with respect to the risk they pose to the ecosystem, or verifies the effects of management measures to improve the ecological status (Agostini et al. 2006). Early warning strategies on the basis of sub-lethal effects in vitro and in vivo are provided by the combination of fractionation and analytical tools for the effect-directed analysis of key toxicants. Integrated assessment of the exposure and effects of a given pollutant on biofilms, invertebrates and fish communities, linking chemical analysis in water, sediment and at the community level, influence this analysis in a manner which is designed to provide data and conceptual understanding of the risk arising from toxicants (Brack et al. 2005). Therefore, Modelkey DSS is mainly an assessment system, and it provides support to specific phases of the decision making framework (Agostini et al. 2006). For data evaluation, Modelkey DSS provides a database of environmental and socio-economic data, which can also be mapped in a GIS environment and is therefore useful for the spatial characterization of hot spots. The results of the integrated assessment phase, in the form of integrated indices and site-specific risk indices, feed into the management phase that mainly concerns the development of the River Basin Management Plans (Agostini et al. 2006).

The Total Maximum Daily Load (TMDL) program was established under the U.S. Clean Water Act (CWA), focusing on the identification and restoration of polluted surface water bodies, including rivers and streams (U.S. Environmental Protection Agency 1991), and it has been used extensively by the U.S. EPA and state environmental agencies in implementing the CWA, by establishing maximum pollution limits for industrial wastewater discharges (Wikipedia 2012). Development of TMDL is a significant undertaking in watershed management, and TMDL implementation planning is critical in accomplishing watershed management objectives (Clark 2002). Chen et al. (1999) developed a DSS to calculate TMDLs in the Catawba River Basin, which extends from North Carolina to South Carolina. Lee (2006) developed TMDL Calculation and Allocation Decision Support System (TCADSS) to provide an automatic capability to calculate and allocate the pollutant loads for watershed TMDL management. In the system, the phosphorus TMDL development for Echo Reservoir was presented as a case study to demonstrate how TCADSS could be used to calculate phosphorus loads, analyze the relative pollutant contribution, and al- locate responsibility of load reduction under three different allocation methods using cost-effectiveness analysis for nine sub-watersheds.

\section{DISCUSSION AND CONCLUSION}

Various DSSs have been developed with diverse objectives. Contemporary DSSs have several attributes (Power 2009): 1) multiple, remote users can collaborate in realtime using rich media, 2) users can access DSS applications anywhere and anytime, 3) users have fast access to historical data stored in very large datasets, 4) users can view data and results visually with excellent graphs and charts, and 5) users can receive real-time data when needed.

The Ministry of Environment, Korea, has planned "The Korea National Environmental Health Action Plan toward 10 years (KNEHAP-10) (2006-2015)" in order to better protect the environment (Ministry of Environment, Korea 2009). It is the nation's fundamental policy for the improvement of water environments including rivers, lakes, and coastal water system. This governmental plan is central to the nation's future water environmental management, as are the guidelines for regional environment management offices and local governments to make water quality management policy. Therefore, it is timely, necessary, and important to develop and to install a DSS for sustainable aquatic ecosystem management. The review on the characteristics of DSSs revealed that the DPSIR framework was implemented in the majority of the European DSSs, and that different DSSs have different objectives and structures. Most DSSs are based on the river basin level, indicating that aquatic ecosystem management should be conducted at basin level. Tools and models have also changed into integrated management systems which consider all effects, including socioeconomic, physical, and chemical changes in aquatic ecosystem. Recently, GIS and MCA were commonly used to analyze the conditions of aquatic ecosystems more accurate and promptly, and many online systems have been developed.

The process of decision making is a combination of consideration of a system (e.g., river), the decision maker, and the problem at hand, and it also should consider the gap between the actual-state and the desired-state of affairs (Salewicz and Nakayama 2004). Therefore, these three factors should be deliberately considered in the development of a DSS, and should be used to determine the correct course of action within complicated systems. 
Although new DSSs are continuously being developed, incorporating the latest technologies, there is a critical element of functionality and appropriateness which can be absent from such systems (Loucks 1995).

It is critical to incorporate the environmental hazard ratings of harmful chemical substances within such a system. There remains, however, the task of establishing a system for the relative comparison of all toxic substances. The examination of all environmental criteria is necessary for the effective implementation and operation of the integrated environmental management policy. Furthermore, it is necessary to reduce the risk of harmful chemical substances and to control them safely. Especially, for the adherence to Integrated Pollution Prevention and Control (IPPC) for harmful chemical substances, every action should be taken to safeguard aquatic ecosystems by determining the characteristics and the locations of emission sources and ecological resources, and the effects of emission (Korea Environment Institute 2004).

In this study, we evaluated the characteristics of contemporary DSSs for the management of aquatic ecosystems. Various DSSs have been developed with different objectives and different tools, and the development of technology and social requirements were reflected in the development of DSSs. In Korea, there is currently both motive and incentive for the development of an integrated DSS for aquatic ecosystem management. Moreover, it is important to develop an individual DSS for site-specific management and national monitoring systems. In the development of DSSs, the factors chosen by researchers and policy makers should be aimed at narrowing the gap between stakeholder opinions, as well as establishing feasible policy for the protection of out waterways.

\section{AKNOWLEDGMENTS}

This work was supported by the National Research Foundation of Korea (NRF) grant funded by the Korea government (MEST) (No. 2010-0027360).

\section{LITERATURE CITED}

Achleitner S, De Toffol S, Engelhard C, Rauch W. 2005. The European water framework directive: water quality classification and implications to engineering planning. Environ Manage 35:517-525.

Agostini P, Semenzin E, Critto A, Micheletti C, Nunes P, Ghermandi A, Gottardo S, Glove S, de Zwart D, Brack W,
Marcomini A. 2006. Models for Assessing and Forcasting the Impact of Environmental Key Pollutants on Marine and Freshwater Ecosystems and Biodiversity, DD1.11 Review of Models/Tools/Decision Frameworks and Conceptual Frameworks. Modelkey, Leipzig.

Allen P, Bennett B, Carrilllo M, Goeller B, Walker W. 1992. Quality in policy modeling. Interfaces 22: 70-85.

Andreu J, Capilla J, Sanchís E. 1996. AQUATOOL, a generalized decision-support system for water-resources planning and operational management. J Hydrol 177: 269291.

Arumugam N, Mohan S. 1997. Integrated decision support system for tank irrigation system operation. J Water Resour Plann Manage 123: 266-273.

Brack W, Bakker J, de Deckere E, Deerenberg C, van Gils J, Hein M, Jurajda P, Kooijman B, Lamoree M, Lek S, López de Alda MJ, Marcomini A, Muñoz I, Rattei S, Segner H, Thomas K, von der Ohe PC, Westrich B, de Zwart D, Schmitt-Jansen M. 2005. Modelkey: models for assessing and forecasting the impact of environmental key pollutants on freshwater and marine ecosystems and biodiversity. Envrion Sci Pollut Res Int 12: 252-256.

Carlon C, Critto A, Ramieri E, Marcomini A. 2007. DESYRE: decision support system for the rehabilitation of contaminated megasites. Integr Environ Assess Manag 3: 211-222.

Chen WC, Herr J, Ziemelis L, Goldsetin RA, Olmsted L. 1999. Decision support system for total maximum daily load. J Environ Eng 125: 653-659.

Clark DL. 2002. TMDL implementation plans and decision support systems to track projects and best management practices. Proceeding of National TMDL Science and Policy Conference, 2002 Nov 13-16, Phoenix, AZ. Water Environment Federation, Alexandria, VA.

Critto A, Cantarella L, Carlon C, Giove S, Petruzzelli G, Marcomini A. 2006. Decision support-oriented selection of remediation technologies to rehabilitate contaminated sites. Integr Environ Assess Manag 2: 273-285.

Davis JR, Nanninga PM, Biggins J, Laut P. 1991. Prototype decision support system for analyzing impact of catchment policies. J Water Resour Plann Manage 117: 399414.

Dietrich J, Schumann A, Lotov A. 2004. Workflow oriented participatory decision support for the integrated river basin planning. Proceeding of the IFAC Workshop Modelling and Control for Participatory Planning and Managing Water Systems, 2004 Sep 29-Oct 1, Venice.

Dunn SM, Mackay R, Adams R, Oglethorpe DR. 1996. The hydrological component of the NELUP decision-support system: an appraisal. J Hydrol 177: 213-235. 
Eom HB, Lee SM. 1990. A survey of decision support system applications (1971-April 1998). Interfaces 20: 65-79.

European Environmental Agency. 1999. Environmental Indicators: Typology and Overview. Technical Report No. 25. EEA, Copenhagen.

European Union. 2000. Directive of the European Parliament and the Council Establishment a Framework for Community Action in the Field of Water Policy. ENV221 CODEC 513. Legislative Acts and Other Instruments, EU, Brussels.

Ford DT, Killen JR. 1995. PC-based decision-support system for Trinity River, Texas. J Water Resour Plann Manage 121: 375-381.

Fredericks JW, Labadie JW, Altenhofen JM. 1998. Decision support system for conjunctive stream-aquifer management. J Water Resour Plann Manage 124: 69-78.

Giove S, Agostini P, Critto A, Semenzin E, Marcomini A. 2007. Decision support systems for the management of contaminated sites: a multi-criteria approach. In: Environmental Security in Harbors and Costal Areas: Management Using Comparative Risk Assessment and Multi-criteia Decision Analysis (Linkov I, Kiker GA, Wenning RJ, eds). Springer, Amsterdam, pp 267-273.

Giupponi C. 2007. Decision support systems for implementing the European water framework rirective: The MULINO approach. Environ Model Softw 22: 248-258.

Heathcote IW. 1998. Integrated Watershed Management: Principles and Practice. Wiley \& Sons, New York.

Hodges JS. 1991. Six (or so) things you can do with a bad model. Oper Res 39: 355-365.

Ito K, Xu ZX, Jinno K, Kojiri T, Kawamura A. 2001. Decision support system for surface water planning in river basins. J Water Resour Plann Manage 127: 272-276.

Jamieson DG, Fedra K. 1996a. 'The Waterware' decisionsupport system for river basin planning. 1. Conceptual design. J Hydrol 177: 163-175.

Jamieson DG, Fedra K. 1996b. 'The Waterware' decisionsupport system for river basin planning. 3. Example applications. J Hydrol 177: 199-211.

Jansen RA, Krejcik J, Malmgren-Hansen A, Vanecek S, Havnoe K, Knudsen J. 2002. River basin modelling in the Czech Republic to optimise interventions necessary to meet the EU environmental standards. Proceedings of the International Conference of Basin Organizations, 2002 Nov 4-6, Madrid.

Korea Environment Institute. 2004. Multimedia Environmental Quality Criteria for the Integrated Environmental Management of Hazardous Chemicals. Korea Environment Institute, Seoul. (Korean with English summary)
Kim YO, Um HI, Yoo SY. 2007. Analyzing an Inactive Practical Use of Model and Its Improvements. Division of Water Resource Systems, Daejeon, pp 75-122.

Labadie JW, Brazil LE, Corbu I, Johnson LE. 1989. Computerized Decision Support Systems for Water Managers. American Society of Civil Engineers, New York.

Lahmer W. 2004. Multi-disciplinary approaches in river basin management: an example. Presentation at the International Conference on Water Observation and Information System for Decision Support, 2004 May 25-29, Ohrid, Macedonia.

Lee B. 2006. Total maximum daily load (TMDL) calculation and allocation decision support system (TCADSS) for watershed TMDL development. MS Thesis. Utah State University, Logan, UT, USA.

Loucks DP. 1992. Water resource systems models: their role in planning. J Water Resour Plann Manage 118: 214-223.

Loucks DP. 1995. Developing and implementing decision support systems: a critique and a challenge. Water Resour Bull 31: 571-582.

Loucks DP, da Costa JR. 1991. Decision Support Systems: Water Resource Planning, NATO Series G 26. SpringerVerlag, Berlin, Heidelberg.

Ministry of Environment, Korea. 2009. The Korea National Environmental Health Action Plan toward 10 Years (KNEHAP-10) (2006-2015). MOE, Gwacheon.

Moltgen J, Rinke K. 2004. Landscape editing for planning support in river basin management: FLUMAGIS. Complexity and Integrated Resources Management, Transactions of the 2nd Biennial Meeting of the International Environmental Modelling and Software Society, 2004 Jun 14-17, Osnabruck. iEMSs, Manno.

Mysiak J. 2005. Development of transferable multicriteria decision tools for water resource management. International Workshop on Success and Failure of Decision Support Systems for Integrated Water Resource Management, 2005 Oct 6-7, Palazzo Zorzi, Venice.

Organizational Aspects of Information Technology Special Interest Group. 1996. The performance of information technology and the role of human and organizational factors. OASIG, Sheffield.

Power DJ. 2007. A brief history of decision support systems. http://dssresources.com/. Accessed 23 June 2012.

Power DJ. 2009. Decision Support Basics. Business Expert Press, New York.

Raymond RC. 1966. Use of the time-sharing computer in business planning and budgeting. Manag Sci 12: B363B381.

Reitsma RF. 1996. Structure and support of water-resources management and decision-making. J Hydrol 177: 253- 
268.

Salewicz KA, Nakayama M. 2004. Development of a webbased decision support system (DSS) for managing large international rivers. Glob Environ Chang 14(Supplement): 25-37.

Santos MA. 1991. Decision Support Systems in Water Resources. Laboratorio Nacional de Engenharia Civil, Lisboa.

Scott Morton MS. 1967. Computer-driven visual display devices: their impact on the management Decision-making process. PhD Dissertation. Harvard Business School, Boston, MA.

Semenzin E, Critto A, Rutgers M, Marcomini A. 2007. DSSERAMANIA: a decision support system for site-specific ecological assessment of contaminated sites. In: Strategies to Enhance Environmental Security in Transition Countries (Hell RN, Barbu CH, Goncharova N, eds). Springer, Amsterdam, pp 35-46.

Shim JP, Warkentin M, Courtney JF, Power DJ, Sharda R, Carlsson C. 2002. Past, present and future of decision support technology. Decis Support Syst 33: 111-126.

Stansbury J, Woldt W, Bogardi I, Bleed A. 1991. Decision support system for water transfer evaluation. Water Resour
Res 27: 443-451.

Turban E. 1967. The use of mathematical models in plant maintenance decision making. Manag Sci 13: B342B358.

U.S. Environmental Protection Agency. 1991. Guidance for Water Quality-Based Decisions: The TMDL Process. Doc. No. EPA 440/4-91-001. U.S. EPA, Washington, DC.

U.S. Environmental Protection Agency. 2004. Better Assessment Science Integrating Point and Nonpoint Sources, Version 3 (BASINS 3.1). Facts Sheet, Office of Water. U.S. EPA, Washington, DC.

Walker WE. 1993. Responsible Policy Modeling. Memo Paper P-7817-1. Rand Corp., Santa Monica, CA.

Watkins DW, McKinney DC. 1995. Recent developments associated with decision support system in water resources. US national report to IUGG, 1991-1994. Rev Geophys 33(Suppl): 941-948.

Westphal KS, Vogel RM, Kirshen P, Chapra SC. 2003. Decision support system for adaptive water supply management. J Water Resour Plann Manage 129: 165-177.

Wikipedia 2012. Total maximum daily load. http://en.wikipe dia.org/wiki/Total_maximum_daily_load. Accessed 23 June 2012. 